\title{
Conceptualizing Faculty Adaptability in Enacting Curricular Change
}

\section{Hadi Ali, Arizona State University}

Hadi studies the influence of the future of work on curricular innovation, with a focus on exploring the relationships between and among adaptability, risk taking and value making. In an effort to characterize engineering education as an (eco)system for creating value, Hadi's approach integrates analytical methods of data science to address changes in systems and society. More broadly, Hadi is interested in examining how engineering innovations mobilize social and economic change. Hadi has graduate degrees in Aeronautics and Astronautics (space systems design, astrodynamics and propulsion), Electrical and Computer Engineering (artificial intelligence, fields and optics) and Engineering Education (design cognition and human communication inquiry) all from Purdue University. He also has an undergraduate degree in Mechanical Engineering (design) from the University of Jordan, and an undergraduate degree in Aeronautics and Astronautics from Purdue. He taught courses in use-inspired design at ASU and in transforming ideas to innovations at Purdue. Prior to joining ASU, Hadi worked at the University of Jordan as a facilitator for curricular change and design content instructor at the Department of Mechatronics. He was on the management team of the Amman Design Week in its inaugural year in Jordan, launched by Queen Rania-a pioneering platform that harnessed creativity, revived the conversation about design, and instilled a spirit of collaboration and exchange.

\section{Dr. Ann F. McKenna, Arizona State University}

Ann F. McKenna is the Vice Dean of Strategic Advancement for the Ira A. Fulton Schools of Engineering at Arizona State University, and is a professor of engineering in the Polytechnic School, one of the six Fulton Schools. Prior to joining ASU she served as a program director at the National Science Foundation in the Division of Undergraduate Education, and was the director of education improvement in the McCormick School of Engineering at Northwestern University. Dr. McKenna received her B.S. and M.S. degrees in Mechanical Engineering from Drexel University and Ph.D. from the University of California at Berkeley.

\section{Dr. Jennifer M. Bekki, Arizona State University}

Jennifer M. Bekki is an Associate Professor in The Polytechnic School within the Ira A. Fulton Schools of Engineering at Arizona State University. Her research interests include topics related to engineering student persistence, STEM graduate students (particularly women), online learning, educational data mining, and the modeling and analysis of manufacturing systems. She holds a bachelor's degree in Bioengineering and graduate degrees in Industrial Engineering, all from Arizona State University.

\section{Dr. Rod D. Roscoe, Arizona State University}

Rod Roscoe is an Associate Professor of human systems engineering in the Polytechnic School of the Ira A. Fulton Schools of Engineering, and a Diane and Gary Tooker Professor of Effective Education in STEM. He is affiliate faculty of the Mary Lou Fulton Teachers College, and a member of the Center for Gender Equity in STEM (CGEST) and the Center for Human, Artificial Intelligence, and Robot Teaming (CHART). His research investigates how the intersection of learning science, computer science, and user science can inform effective and innovative uses of educational technologies. He is also interested in how engineering education can better prepare future engineers to consider the human elements and impacts of their work, particularly with respect to more equitable and inclusive outcomes. 


\title{
Conceptualizing faculty adaptability in enacting curricular change
}

\begin{abstract}
In this theory paper, we seek to conceptualize faculty adaptability as self-regulation during curricular change. We highlight the expanded set of responsibilities that faculty engage with as part of their effort to (re)shape the engineering curriculum. Based on the literature, we illustrate how adaptability is multifaceted; it has different aspects that are manifested differently in different contexts. Moreover, this research conceptualizes a university as an environment that represents dynamic contexts. Consequently, faculty do not have fixed tasks; rather, they engage in broad roles. Although knowledge about effective teaching and learning exists, and theories of change strategies are considered, the lack of the understanding of the behavior of engineering faculty as change agents, and as the unit of analysis, during the process of change, remains a major contributor against more robust change efforts. Without the comprehensive understanding of the adaptability of key change agents in the educational system, and as they respond to dynamic and changing contexts, the effective enacting of curricular change initiatives remains unfulfilled. Ultimately, we aim to use this conceptual model to compare faculty adaptability in different contexts of curricular change.
\end{abstract}

\section{Calls for change in engineering education: Enabling change agents}

Calls for change in engineering education has constantly been shaped by "changing times and paradigms" (Felder, 2004, p. 32). The context within which engineering graduates are educated, and are expected to contribute in the workplace, has always been a dominant factor in frameworks for calls for change (Jamieson \& Lohmann, 2009). Characteristics of the context such as the influence of the global economy, the knowledge-based economy, changing demographics, increased integration among engineering disciplines and environmental factors are just some examples (Katehi et al., 2004). In many of the national reports that call for change in engineering education, the lack of preparation of engineering graduates to address the challenges of a changing world are cited (e.g., Duderstadt, 2008; National Academy of Engineering [NAE], 2005; National Research Council [NRC], 2007; National Science Board [NSB], 2007; Nielsen, 2011). The reports do not only cite the quality of outcomes but also point the to the lack of comprehensive understanding of the learning process (e.g., NAE, 2005) affecting both the design of the engineering curriculum and the delivery of the curriculum (Duderstadt, 2008).

In addition to characterizing the problem, national as well as international calls for change, tend to provide solutions in the form of recommendations. Proposed recommendations include addressing pedagogy issues, such as student-centeredness and authentic learning experiences, which integrate into the curriculum the humanities, global competencies, teamwork and communication skills (Borri \& Maffioli, 2007; King, 2008; Nielsen, 2011). However, challenges exist in implementing these recommendations (Borrego, Froyd, \& Hall, 2010; NSF, 2008). Recommendations characterize what engineering education should look like with little attention to how to implement change (ASEE, 2009). See, for example, a list of recommendations provided by the ASEE report on Creating a culture for scholarly and systematic innovation in engineering education (2009), Table 1 . The suggested actions are listed for engineering faculty, chairs and deans. The recommendations are provided in broad terms without clear articulation of the realization process of these aspirations. Investments in understanding effective pedagogies have been made (Borrego et al., 2010; NRC, 2012; Prince \& Felder, 2006). However, challenges continue to exist for faculty to adopt and scale research-based pedagogies and interventions (ASEE, 2009; 2012; NRC, 2012; PCAST, 2012). The same ASEE report (2009) cites the following quote about the hardest part of change: 
"The hard part of being adaptive and innovative is that often it forces us to change ourselves, our environments, or both. These changes can evoke strong emotions and take us away from our momentary efficiencies and comfort zones by forcing us to unlearn old skills, [and] tolerate momentary chaos and ambiguity in order to move forward..." (Bransford, 2007, p. 2)

Table 1. Suggested actions for individuals in the educational system, including faculty, offered as recommendations for change in engineering education. Suggested actions often lack clear mechanism for implementation. (ASEE, 2009)

\begin{tabular}{ll}
\hline Stakeholder & \multicolumn{1}{c}{ Suggested action } \\
\hline Engineering faculty, chairs, & - Link engineering education practice and research \\
and deans & - Support and recognize educational innovation \\
& - Prepare future faculty \\
& - Integrate the curriculum \\
& - Eromote learning through entrepreneurship \\
& - Develop leaders \\
& - Promote learning through service \\
& - Enhance faculty experience \\
\hline
\end{tabular}

There is a need to understand the enablers and barriers for individual faculty to change. Two related factors that contribute to the challenge of implementing change are the status-quo, represented by organizational structures and systems that make up the educational process (Borrego et al., 2010; NSB, 2007) and change agents, represented by faculty and administration leaders who are willing to embrace change efforts while viewing these efforts as scholarly-sound and as based on research (Borrego \& Henderson, 2014). In the past, the problem of enabling faculty and administration leaders to emerge as change agents to change the status quo has been characterized as a "shift" in emphasis from teaching to learning (Seymour, 2002) and as "maintaining balance" between theory and practice (Reynolds \& Seely, 1993; Seely, 1999). However, efforts to guide faculty and administration leaders in the change process remain implicit (Borrego \& Henderson, 2014). Although knowledge about effective teaching and learning exists, and theories of change strategies are considered, the lack of the understanding of the behavior of change agents, as a unit of analysis, during the process of change, remains a major contributor against more robust change efforts. Without the comprehensive understanding of the adaptability of key change agents in the educational system, and as they respond to dynamic and changing contexts, the effective enacting of curricular change initiatives remains unfulfilled.

\section{Faculty roles and contributions to curricular change}

In order to effectively implement proposals for curricular change, a careful understanding of the relationship between stakeholders and the curriculum is necessary. Henderson et al. (2010, 2011) developed a categorization of strategies used to create change in STEM education. Based on their categorization, which is developed after reviewing 191 journal articles published between 1995 and 2008 on the topic, change strategies can be mapped into one of four categories: disseminating pedagogy; developing reflective teachers; enacting policy; and developing a shared vision. The categorization by Henderson et al. $(2010,2011)$ is consistent with other efforts to categorize theories of change (e.g., Amundsen \& Wilson, 2012) and has been utilized by Borrego \& Henderson (2014) to identify ways to increase the use of evidence-based teaching in engineering education. Most importantly, the framework highlights the efforts of faculty as agents for change in all four categories. However, while the several theories are provided as suggestions for change patterns in engineering education, the link between faculty (as active agents for change) and the curriculum (as an embodiment of many of the assumptions of 
the educational system) remains implicit. While change strategies consider various stakeholders, the central role that faculty play during the process remains generic and prescriptive without emphasis on how faculty actually respond to calls for change.

Understanding faculty roles and contribution to curricular change requires understanding the complexity in developing the "ideal curriculum." The engineering curriculum went through different waves of transformation (see, for example, Seely, 1999, 2005; Seymour, 2002; Wankat, 2004). A common theme has been bridging the gap between the preparation of graduating engineers and the needs of the workplace (Seely, 2005). The question of the fit between engineering faculty, with their focus on engineering science, and their ability to translate the theoretical applications in ways that are effective for preparing engineers has always been of concern (Walker, 1989). In the past, in most engineering curricula, students did not interact with engineering faculty until late in their sophomore year. Initial efforts to focus on design courses in the first year in the curriculum was an attempt to allow students to interact with engineering faculty early in the curriculum (Agogino, Sheppard, \& Oladipupo, 1992; Pavelich, Olds, \& Miller, 1995). At the same time, challenges started to emerge to effectively integrate design into the engineering curriculum (e.g., Crawley, 2002) and to identify effective ways for assessment (Dym et al., 2005). Some faculty were comfortable engaging in a pedagogy based on project-based learning (PBL) (Smith et al., 2005). Employers started to recognize the qualities that PBL provides for students, including communication, teamwork skills and interest in life-long learning (Oakes, Coyle, \& Jamieson, 2000; Smith, 2004).

The constantly changing nature of the engineering curriculum, in concert with economic, social and global contexts, continuously call for engineering faculty to adapt, by incorporating new content as well as utilizing effective educational interventions. A recent study on The Global State of the Art in Engineering Education identified features that distinguish current leaders and emerging leaders in engineering education by comparing their different curricular approaches (Graham, 2018). Some of the identified curricular features included design- and make-based learning, collaborative cultures, academic rigor in the engineering fundamentals, multidisciplinarity, work-ready environments and self-directed learning (Graham, 2018). Additionally, pedagogical features associated with current leaders included "technology-based extra-curricular activities" and "emerging capabilities in online and blended learning" (p. 30). The expansive and evolving nature of the engineering curriculum, in terms of both content and form, points to the changing nature of the role of faculty.

The engineering curriculum exists in a context; many of the change calls are initiated by external factors influencing the engineering curriculum. However, the actual realization of these calls falls upon the engineering faculty as change agents. Without the contribution of faculty, the implementation of change is not robust (Besterfield-Sacre et al., 2014). Faculty are being asked to engage in structured change efforts (Henderson, Finkelstein, \& Beach, 2010), to work together in interdisciplinary groups (Henderson et al., 2008) and to become partners in the change process (Henderson \& Dancy, 2008; Henderson et al., 2010). However, while there is a recognition of the fundamental role that faculty play, no sufficient attention has been given to their adaptability in response to change.

Individual characteristics have been identified as a constraint on faculty's willingness to engage in change (Murray \& Macdonald, 1997; Norton et al., 2005; Prosser \& Trigwell, 1999). Furthermore, the reward system and the already existing expectations in the engineering disciplines have been brought into attention as barriers to change (Besterfield-Sacre et al., 2014). Faculty have an individual agency to make decisions that is not usually attuned to in change proposals (Kezar \& Eckel, 2002; Wejnert, 2002). Different change proposals assume immediate adoption from faculty, when in reality the lack of willingness to adapt, or only superficial adoption results in ineffective change (Henderson, 2005; Henderson \& Dancy, 2005; Seymour, DeWelde, \& Fry, 2011). Table 2 lists aspects of the role of faculty that are not considered early in calls for change and end up being considered as barriers for change. 


\section{Table 2. Faculty attributes as conceived in the literature to be barriers to change.}

(Adapted from Besterfield-Sacre et al., 2014).

\section{Faculty attributes that are cited as barriers to change}

- Expectations of content coverage

- Limited instructor time

- Lack of training

- Departmental norms

- Dealing with student resistance

- Dealing with class size and room layout

- Time structure

- Institutional reward system

- Institutional culture

- Research priorities

\section{Studying faculty adaptability}

Adaptability can be broadly defined as the willingness to change behavior. The change in behavior can be either in response to change in the environment, reactively (Pulakos et al., 2000), or for making necessary modifications to attain new goals, proactively (Griffin and Hesketh, 2003). Because this study focuses on examining faculty's ability to respond to curricular change in different contexts, understanding performance adaptability in dynamic and changing situations is necessary. Research over the past two decades on performance adaptation has witnessed substantial growth, with the majority of the research coming from management and organizational literature (Baard, Rench, \& Kozlowski, 2014). Adaptability has been described as a phenomenon that can be promoted at the individual- (Macey \& Schneider 2008; Shoss et al., 2012; Stokes et al.; 2010), team- (Driskell et al., 2006; Wiedow \& Konradt, 2011), and organizational levels (Birdi et al., 2008; Sonenshein, 2010). Internal and external factors have been found to influence the nature (what), levels (where) and mechanisms (how) of adaptation (Baard et al., 2014).

Following the conceptual taxonomy developed by Baard et al. (2014), performance adaptability as a phenomenon can be viewed from a domain-general perspective or domain-specific perspective. The domain-general perspective situates adaptability as a generic capability with the underlying assumption that adaptability is a stable trait which can be generalized across domains (Ployhart \& Bliese, 2006; Pulakos et al., 2000; Pulakos et al., 2002). In this generic perspective, adaptability was examined by (1) studying job performance of individuals; or (2) by comparing adaptability across individuals. Alternatively, in the domain-specific perspective, adaptability is assumed to require knowledge and skills that are unique to the domain within which it is applied (Holyoak, 1991; Kanfer \& Ackerman, 1989). In this specific perspective, adaptability was examined by (1) comparing change in performance from routine to novel tasks; or (2) observing change of performance as a process over time.

Because most of studies on adaptability come from the literature in management and organizational theory, a gap exists in the study of faculty adaptability. Adaptation is a broad concept that can be applied to different levels of organizational structures. As described before, a significant portion of the literature describes aspects of faculty willingness to change (e.g., Clark et al., 2004; Matusovich et al., 2014) or reflective practice (Borrego, 2007; Mettetal, 2001). However, in the proposed conceptualization of faculty adaptability, the focus is on integrating mechanisms of adaptation as applied to faculty responses as active individuals in curricular change. Faculty members are unique in an organizational structure for different reasons. First, their level of commitment is not always for the institution they work for as they are members of broad research communities and fields of study. Second, faculty members possess higher 
levels of autonomy which enable them to work with minimal supervision compared to other professions. Third, faculty members motivation for change (or response to change) is largely driven by research and discovery and not just by the desire to be promoted in an organizational hierarchy or to fulfill prescribed tasks. All these factors make the study of faculty adaptability a unique one and one of interest.

\section{Conceptualizing adaptability as self-regulation}

\subsection{Self-regulation as a framework: Underlying assumptions}

Self-regulation involves the active construction of goals from the given information in the external environment (Azevedo, 2009; Pintrich, 2000; Zimmerman, 1986, 1989, 1990, 1994). It has been used widely in the learning sciences to study mechanisms of learning. Some of the underlying assumptions of self-regulation as a framework is that learners are active in constructing goals and attempting to achieving them; that learners have control over their learning through their ability to monitor, control and regulate their learning; and that there is goal or criterion which provides the standard for assessing regulation. One more assumption underlying self-regulation is that regulatory activities act as mediators between the person and the context within which the person exists (Pintrich, 2000). This assumption is particularly important in this study where faculty adaptability is viewed to be context driven.

\subsection{Models for self-regulation and link to the study of adaptability}

Several models for self-regulation exist. The triadic model, for example, links the person, self-behavior and the environment (Zimmerman, 1989). In a refined model by Zimmerman (2000), self-regulation takes a cyclical phase model, where forethought leads to performance, followed by self-reflection, Figure 1. The Winne and Hadwin model (1998) provides more granularity by including monitoring and control within each phase of learning while delineating between task definition and goal setting (Greene, \& Azevedo, 2007). Pintrich (2000) provides an overview of the common themes of models of selfregulation, where models can be organized along two dimensions: (1) phases of regulation, which include forethought (planning or activation); monitoring; control; and reaction (reflection); and (2) areas of regulation, which include cognition; motivation; behavior; and context.

\subsection{Proposed model to study faculty adaptability as self-regulation}

Our revised self-regulation model in adaptability is shown in Figure 2 below. It is inspired by the cyclical model proposed by Zimmerman (2000); however, it is modified to include a willingness aspect for each phase of the cycle. A similar modification has already been proposed by Zimmerman \& Moylan (2009) who observed that individuals in demanding contexts seek personal initiative and involve more motivational aspects than passive engagement. Their modified framework added self-control and selfobservation in each phase. In the forethought (or planning) phase, in particular, they added task analysis of self-motivation beliefs as part of the phase. The operationalization of the definition of each phase as it applies to faculty adaptability is provided in Table 3. In the discussion below, the integration in the revised model of faculty willingness to engage in each phase of self-regulation as adaptation in curricular change is highlighted.

Willingness for planning in curricular change involves significant attention to the allocation of time and effort. Planning is conceptualized in models of intentions and intentional planning as a behavioral intention (e.g., Gollwitzer, 1996). In such models, willingness for planning represents a formation of intention that is linked to subsequent behaviors (Ajzen, 1988, 1991) and is largely based on theories of achievement motivation (Ames, 1992; Dweck \& Leggett, 1988; Wolters, Yu, \& Pintrich, 1996). Willingness for adjusting in curricular change represents the faculty's control and regulation of behavior. Adjusting has the aspect of persistence (Karabenick \& Sharma, 1994) and is an indicator for motivation 
(Nelson-Le Gall, 1981, 1985). The link between adjusting, as a behavioral area of regulation, and willingness, as an affective area of regulation, can be explained as an attempt to "control anxiety and selfworth" (Pintrich, 2000, p. 468) in anticipation of reward or in avoidance of consequences (Weiner, 1986; Zimmerman \& Kitsantas, 1997). Willingness for reflecting on curricular change involves observing one's performance, with the motivation of assessing outcomes with respect to goals (Baker 1979; 1989; Schneider \& Pressley, 1997; Schraw et al., 1995). An environment that enables self-observation (Zimmerman \& Martinez-Pons, 1986) and self-experimentation (Zimmerman, 1998, 2000) during the activity is usually an environment that induces effective self-monitoring.

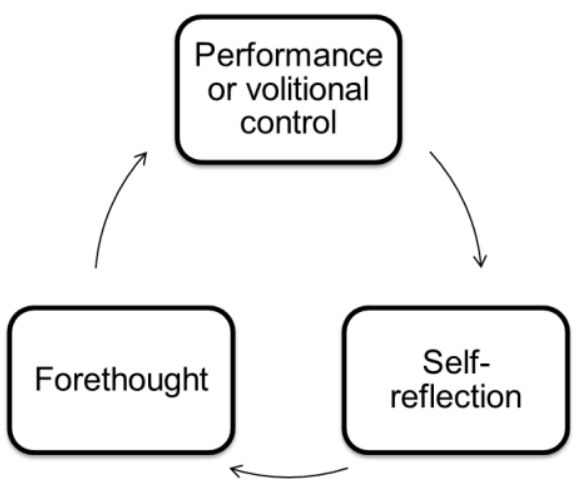

Figure 1. The cyclical phase model of self-regulation (Zimmerman, 2000).

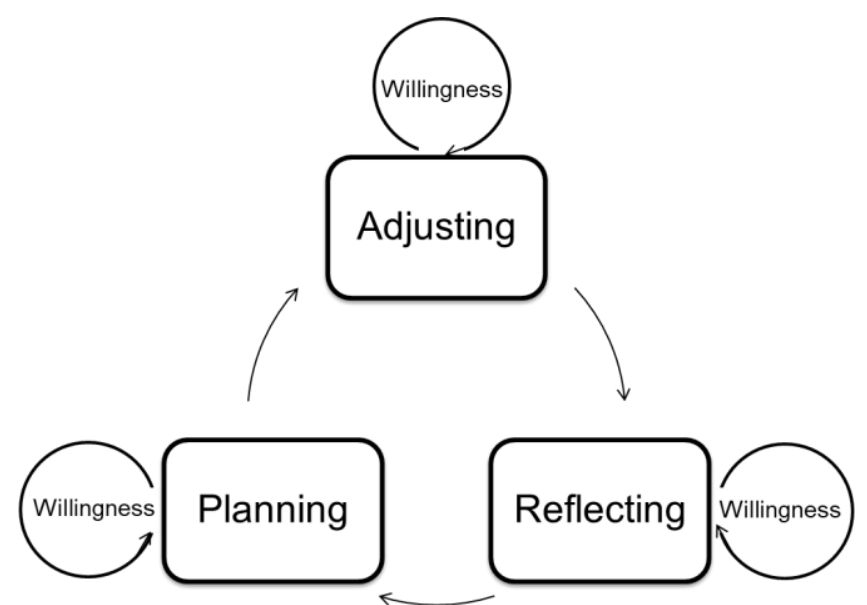

Figure 2. Conceptualization of adaptability as self-regulation in this study. 


\section{Table 3. Operational definitions for the various phases of self-regulation for the purpose of study faculty}

Phase

Planning

Self-reflection

Adjusting

Willingness

\section{Definition}

\section{adaptability.}

Planning involves target goal setting of task-specific goals that can be used to guide behavior, in general, and for monitoring, in particular

Self-reflection is the efficacy of exhibiting cognitive judgement and change of behavior as a result of affective reaction, evaluation of tasks or evaluation of context

Adjusting is the efficacy of changing behavior due to observed negative discrepancies between a goal and current state

Willingness involves being open to change and acting based on plans, previous information or other internal or external factors

\section{Summary and future work: developing an instrument for studying context-driven adaptability}

Faculty are being asked to engage in a variety of activities that are changing in nature and scope (ASEE, 2012; NAE, 2005; PCAST, 2012). Calls for change in engineering education continue to ask of faculty to master an expanded set of responsibilities. Role theory contrasts between fixed, formalized tasks, which can be evaluated in terms of proficiency behavior, and emergent work roles, which can be evaluated in terms of adaptive behavior (Ilgen \& Hollenbeck, 1991). In this framing, the nature of work roles is linked with the contexts in which they exist (Griffin, Neal, \& Parker, 2007).

Faculty members tend to value autonomy; self-driven innovations (vs. administrative-driven); inclusive opportunities for feedback; community; recognition and efficacy (Bolman \& Deal, 1991; Borrego \& Henderson, 2014; Guerra et al., 2014). The context of curricular change shapes the behavior that is valued in the organization for effective work (Scott \& Davis 2015; Thomson, 2003). Previous studies of change in engineering education did not account for the full range of behaviors that faculty are expected to contribute in order for successful implementation of change (Borrego et al., 2010; NRC, 2012; Prince \& Felder, 2006). Challenges exist in the implementation of effective strategies, including adoption and scaling-up, where faculty emerge as central change agents in affecting change in the college education experience (Bekki et al., 2017; Borrego \& Henderson, 2014). Future work intends to develop an instrument, based on the conceptualizing of faculty adaptability as self-regulation, to compare faculty adaptability in different curricular change contexts. 


\section{References}

Agogino, A.M., Sheppard, S.D., \& Oladipupo, A. (1992) "Making Connections to Engineering During the First Two Years," Proceedings of the Frontiers in Education Conference. Institute of Electrical and Electronic Engineers (IEEE).

Ajzen, I. (1988). Attitudes, personality, and behavior. Chicago: Dorsey Press.

Ajzen, I. (1991). A theory of planned behavior. Organizational Behavior and Human Decision Processes, 50, 179-211.

American Society for Engineering Education. (2009). Creating a culture for scholarly and systematic innovation in engineering education: Ensuring U.S. engineering has the right people with the right talent for a global society. Washington, DC: American Society for Engineering Education.

American Society for Engineering Education. (2012). Innovation with impact: Creating a culture for scholarly and systematic innovation in engineering education. Washington, DC: American Society for Engineering Education.

Ames, C. (1992). Classrooms: Goals, structures, and student motivation. Journal of Educational Psychology, 84, 261-271.

Amundsen, C., \& Wilson, M. (2012). Are we asking the right questions? A conceptual review of the educational development literature in higher education. Review of Educational Research, 82(1), 90-126. doi: $10.3102 / 0034654312438409$

Azevedo, R. (2009). Theoretical, conceptual, methodological, and instructional issues in research on metacognition and self-regulated learning: A discussion. Metacognition and Learning, 4(1), 87-95.

Baard, S. K., Rench, T. A., \& Kozlowski, S. W. (2014). Performance adaptation: A theoretical integration and review. Journal of Management, 40(1), 48-99.

Baker, L. (1979). Comprehension monitoring: Identifying and coping with text confusions. Journal of Reading Behavior, 11, 365-374.

Baker, L. (1989). Metacognition, comprehension monitoring, and the adult reader. Educational Psychology Review, 1, 3-38.

Bekki, J., Ayela-Uwangue, A., Brunhaver, S., Kellam, N., Lande, M., \& McKenna, A. (2017, June). I want to try that too! Development of a conceptual framework for interventions that encourage pedagogical risk taking among faculty. In ASEE Annual Conference and Exposition, Conference Proceedings (Vol. 2017).

Besterfield-Sacre, M., Cox, M. F., Borrego, M., Beddoes, K., \& Zhu, J. (2014). Changing engineering education: Views of US faculty, chairs, and deans. Journal of Engineering Education, 103(2), 193-219.

Birdi, K., Clegg, C., Patterson, M., Robinson, A., Stride, C. B., Wall, T. D., \& Wood, S. J. (2008). The impact of human resource and operational management practices on company productivity: A longitudinal study. Personnel Psychology, 61: 467-501. 
Bolman, L. G., \& Deal, T. E. (1991). Leadership and management effectiveness: A multi-frame, multi sector analysis. Human Resource Management, 30(4), 509-34.

Borrego, M. (2007). Conceptual difficulties experienced by engineering faculty becoming engineering education researchers. Journal of Engineering Education, 96(2), 91-102.

Borrego, M., Froyd, J. E., \& Hall, T. S. (2010). Diffusion of engineering education innovations: A survey of awareness and adoption rates in U.S. engineering departments. Journal of Engineering Education, 99(3), 185-207.

Borrego, M., \& Henderson, C. (2014). Increasing the use of evidence-based teaching in STEM higher education: A comparison of eight change strategies. Journal of Engineering Education, 103(2), 220-252.

Borri, C., \& Maffioli, F. E. (2007). Re-engineering engineering education in Europe. Florence, Italy: Teaching and Research in Engineering in Europe (TREE): SOCRATES Erasmus Thematic Network.

Bransford, J. (2007). Preparing people for rapidly changing environments. Journal of Engineering Education 96 (1): 1-3.

Clark, M. C., Froyd, J., Merton, P., \& Richardson, J. (2004). The evolution of curricular change models within the foundation coalition. Journal of Engineering Education, 93(1), 37-47.

Crawley, E.F. (2002) "Creating the CDIO Syllabus, A Universal Template for Engineering Education," Proceedings of the 23rd Frontiers in Education Conference. Institute of Electrical and Electronics Engineers (IEEE), Vol. 2.

Driskell, J. E., Goodwin, G. F., Salas, E., \& O’Shea, P. G. (2006). What makes a good team player? Personality and team effectiveness. Group Dynamics: Theory, Research, and Practice, 10: 249-271.

Duderstadt, J. J. (2008). Engineering for a changing world: A roadmap to the future of engineering practice, research, and education: University of Michigan. Retrieved from http://milproj.

ummu.umich.edu/publications/EngFlex\%20report/index.htm

Dweck, C. S., \& Leggett, E. L. (1988). A social-cognitive approach to motivation and personality. Psychological Review, 95, 256-273.

Dym, C., Agogino, A., Eris, O., Frey, D., \& Leifer, L. (2005). Engineering design thinking, teaching, and learning. Journal of Engineering Education, 94(1), 103--120.

Felder, R.M. (2004). Changing times and paradigms. Journal of Chemical Engineering Education, 38(1), $32-33$.

Gollwitzer, P. (1996). The volitional benefits of planning. In P. Gollwitzer \& J. Bargh (Eds.), The psychology of action: Linking cognition and motivation to behavior (pp. 287-312). New York: Guilford.

Graham, R. (2018). The global state of the art in engineering education. Cambridge, MA: Massachusetts Institute of Technology (MIT).

Greene, J. A., \& Azevedo, R. (2007). A theoretical review of Winne and Hadwin's model of selfregulated learning: New perspectives and directions. Review of educational research, 77(3), 334-372. 
Griffin, B., \& Hesketh, B. (2003). Adaptable behaviours for successful work and career adjustment. Australian Journal of Psychology, 55: 65-73.

Griffin, M. A., Neal, A., \& Parker, S. K. (2007). A new model of work role performance: Positive behavior in uncertain and interdependent contexts. Academy of Management Journal, 50: 327-347.

Guerra, R. C. C., Smith, K. A., McKenna, A. F., Swan, C., Korte, R., Jordan, S., ... \& MacNeal, R. (2014, October). Innovation corps for learning: Evidence-based entrepreneurship ${ }^{\mathrm{TM}}$ to improve (STEM) education. In 2014 IEEE Frontiers in Education Conference (FIE) Proceedings (pp. 1-5). IEEE.

Henderson, C. (2005). The challenges of instructional change under the best of circumstances: A case study of one college physics instructor. American Journal of Physics, 73(8), 778-786.

Henderson, C., Beach, A., Finkelstein, N., \& Larson, R. S. (2008). Facilitating change in undergraduate STEM: Initial results from an interdisciplinary literature review. Paper presented at the Physics Education Research Conference, Edmonton, Canada.

Henderson, C., Beach, A., \& Finkelstein, N. (2011). Facilitating change in undergraduate STEM instructional practices: An analytic review of the literature. Journal of Research in Science Teaching, 48(8), 952-984.

Henderson, C., \& Dancy, M. H. (2005). When one instructor's interactive classroom activity is another's lecture: Communication difficulties between faculty and educational researchers. Paper presented at the American Association of Physics Teachers Winter Meeting, Albuquerque.

Henderson, C., \& Dancy, M. H. (2008). Physics faculty and educational researchers: Divergent expectations as barriers to the diffusion of innovations. American Journal of Physics, 76(1), 79-91.

Henderson, C., Finkelstein, N. D., \& Beach, A. (2010). Beyond dissemination in college science teaching: An introduction to four core change strategies. Journal of College Science Teaching, 39(5), 18-25.

Holyoak, K. J. (1991). Symbolic connectionism: Toward third-generation theories of expertise. In K. A. Ericsson and J. Smith (Eds.), Toward a general theory of expertise: 301-336. Cambridge, UK: Cambridge University Press.

Ilgen, D. R., \& Hollenbeck, J. R. 1991. The structure of work: Job design and roles. In M. D. Dunnette \& L. M. Hough (Eds.), Handbook of industrial and organisational psychology ( $2^{\text {nd }}$ ed.): 165-207. Palo Alto, CA: Consulting Psychology Press.

Jamieson, L. H., \& Lohmann, J. R. (2009). Creating a Culture for Scholarly and Systematic Innovation in Engineering Education. Washington, DC: American Society of Engineering Education.

Kanfer, R., \& Ackerman, P. L. (1989). Motivation and cognitive abilities: An integrative/aptitudetreatment interaction approach to skill acquisition. Journal of Applied Psychology, 74: 657-690.

Karabenick, S., \& Sharma, R. (1994). Seeking academic assistance as a strategic learning resource. In P. R. Pintrich, D. R. Brown, \& C. E. Weinstein (Eds.), Student motivation, cognition, and learning: Essays in honor of Wilbert J. McKeachie (pp. 189-211). Hillsdale, NJ: Erlbaum. 
Katehi, L., Banks, K., Diefes-Dux, H., Follman, D., Gaunt, J., Haghighi, K., ... \& Wankat, P. (2004, June). A new framework for academic reform in engineering education. In American Society for Engineering Education Conference Proceedings, Salt Lake City, UT.

Kezar, A. J., \& Eckel, P. D. (2002). The effect of institutional culture on change strategies in higher education: Universal principles or culturally responsive concepts? Journal of Higher Education, 73(4), 435-460.

King, R. (2008). Addressing the supply and quality of engineering graduates for the new century. Sydney, Australia: Carrick Institute.

Macey, W. H.; \& Schneider, B. (2008). The meaning of employee engagement. Industrial and Organizational Psychology, 1: 3-30.

Mettetal, G. (2001). The what, why and how of classroom action research. Journal of the Scholarship of Teaching and Learning, 2(1), 6-13.

Murray, K., \& Macdonald, R. (1997). The disjunction between lecturers' conceptions of teaching and their claimed educational practices. Higher Education, 33, 331-349.

Matusovich, H.; Paretti, M.; McNair L.; \& Hixson, C. (2014) "Faculty motivation: A gateway to transforming engineering education," Journal of Engineering Education, vol. 103, no. 2, pp. 302-330.

National Academy of Engineering. (2005). Educating the engineer of 2020: Adapting engineering education to the new century. Washington, DC: National Academy of Engineering.

National Research Council. (2007). Rising above the gathering storm: Energizing and employing America for a brighter future. Washington, DC: National Research Council.

National Research Council. (2012). Discipline-based educational research: Understanding and improving learning in undergraduate science and engineering. Washington, DC: National Academies Press.

National Science Board. (2007). Moving forward to improve engineering education. Arlington, VA: National Science Foundation.

National Science Foundation. (2008). Innovations in engineering education, curriculum, and infrastructure (IEEECI) NSF (08-542). Arlington, VA: National Science Foundation.

Nelson.Le Gall, S. (1981). Help-seeking: An understudied problem solving skill in children. Developmental Review, I, 224-246.

Nelson-Le Gall, S. (1985). Help-seeking behavior in learning. Review of research in education (Vol. 12, pp. 55-90). Washington DC: American Educational Research Association.

Nielsen, N. (2011). Promising practices in undergraduate science, technology, engineering, and mathematics education: Summary of two workshops. Washington, DC: National Research Council: Planning Committee on Evidence on Selected Innovations in Undergraduate STEM Education.

Norton, L., Richardson, J. T. E., Hartley, J., Newstead, S., \& Mayes, J. (2005). Teachers' beliefs and intentions concerning teaching in higher education. Higher Education, 50, 537- 571. 
Oakes, W.C., Coyle, E.J., \& Jamieson, L.H., (2000). "EPICS: A Model of Service Learning in the Engineering Curriculum," Proceedings of the ASEE Conference and Exhibition.

Pavelich, M.J., Olds, B.M., \& Miller, R.L. (1995) "Real-World Problem Solving in Freshman/Sophomore Engineering," in Gainen, J. and Willemsen, E., (Eds.) Fostering Student Success in Quantitative Gateway Courses, San Francisco, CA.: Jossey-Bass.

Pintrich, P. R. (2000). The role of goal orientation in self-regulated learning. In Handbook of selfregulation (pp. 451-502). Academic Press.

Ployhart, R. E., \& Bliese, P. D. (2006). Individual ADAPTability (I-ADAPT) theory: Conceptualizing the antecedents, consequences, and measurement of individual differences in adaptability. In C. S. Burke, L. Pierce, \& E. Salas (Eds.), Understanding adaptability: A prerequisite for effective performance within complex environments: 3-39. Amsterdam: Elsevier.

President's Council of Advisors on Science and Technology (PCAST). (2012). Engage to excel: Producing one million additional college graduates with degrees in science, technology, engineering, and mathematics. Washington, DC.

Prince, M., \& Felder, R. M. (2006). Inductive teaching and learning methods: Definitions, comparisons, and research bases. Journal of Engineering Education, 95(2), 123-138.

Prosser, M., \& Trigwell, K. (1999). Understanding learning and teaching: The experience in higher education. Buckingham, UK: Society for Research into Higher Education.

Pulakos, E. D., Arad, S., Donovan, M. A., \& Plamondon, K. E. (2000). Adaptability in the workplace: Development of a taxonomy of adaptive performance. Journal of Applied Psychology, 85: 612-624.

Pulakos, E. D., Schmitt, N., Dorsey, D. W., Arad, S., Borman, W. C., \& Hedge, J. W. (2002). Predicting adaptive performance: Further tests of a model of adaptability. Human Performance, 15: 299-323.

Reynolds, T. S., \& Seely, B. E. (1993). Striving for balance: A hundred years of the American Society for Engineering Education. Journal of Engineering Education, 82(3), 136-151.

Schraw, G., Dunkle, M, Bendixen, L, \& Roedel, T. (1995). Does a general monitoring skill exist? Journal of Educational Psychology, 87, 433-443.

Schneider, W., \& Pressley, M. (1997). Memory development between 2 and 20. Mahweh, NJ: Erlbaum.

Scott, W. R., \& Davis, G. F. (2015). Organizations and organizing: Rational, natural and open systems perspectives. Routledge.

Seely, B. E. (1999). The other re-engineering of engineering education, 1900-1965. Journal of Engineering Education, 88(3), 285-294.

Seely, B. E. (2005). Patterns in the history of engineering education reform: A brief essay. Educating the engineer of 2020: Adapting engineering education to the new century, 114-130.

Seymour, E. (2002). Tracking the processes of change in US undergraduate education in science, mathematics, engineering, and technology. Science Education, 86(1), 79-105. 
Seymour, E., DeWelde, K., \& Fry, C. (2011). Determining progress in improving undergraduate STEM education: The reformers' tale. Washington, DC: National Academy of Engineering. Retrieved from http://www.nae.edu/?ID526293

Shoss, M. K.; Witt, L. A.; \& Vera, D. (2012). When does adaptive performance lead to higher task performance? Journal of Organizational Behavior, 33: 910-924.

Sonenshein, S. (2010). We're changing - or are we? Untangling the role of progressive, regressive, and stability narratives during strategic change implementation. Academy of Management Journal, 53: 477512.

Smith, K.A (2004). Teamwork and Project Management, 2nd ed., New York, N.Y.: McGraw-Hill.

Smith, K.A., Sheppard, S.D., Johnson, D.W., and Johnson, R.T. (2005) "Pedagogies of Engagement: Classroom-based Practices," Journal of Engineering Education, 94(1), pp. 87-101.

Stokes, C. K.; Schneider, T. R.; \& Lyons, J. B. (2010). Adaptive performance: A criterion problem. Team Performance Management, 16: 212-230.

Thompson, J. D. (2003). Organizations in action: Social science bases of administrative theory. Transaction publishers.

Walker, E.A. (1989) Now It's My Turn: Engineering My Way. New York: Vantage Press.

Wankat, P. C. (2004). Analysis of the first ten years of the Journal of Engineering Education. Journal of Engineering Education, 93(1), 13-21.

Weiner, B. (1986). An attributional theory of motivation and emotion. New York: Springer-Verlag.

Wejnert, B. (2002). Integrating models of diffusion of innovations: A conceptual framework. Annual Review of Sociology, 28, 297-326.

Winne, P. H., \& Hadwin, A. F. (1998). Studying as self-regulated learning. In D. J. Hacker, J. Dunlosky, \& A. Graesser (Eds.), Metacognition in educational theory and practice (pp. 277-304). Hillsdale, NJ: Lawrence Erlbaum

Wiedow, A., \& Konradt, U. (2011). Two-dimensional structure of team process improvement: Team reflection and team adaptation. Small Group Research, 42: 32-54.

Wolters, C., Yu, S., \& Pintrich, P. R. (1996). The relation between goal orientation and students' motivational beliefs and self-regulated learning. Learning and Individual Differences, 8, 211-238.

Zimmerman, B. J. (1986). Development of self-regulated learning: Which are the key subprocesses? Contemporary Educational Psychology, 16, 307-313.

Zimmerman, B. J. (1989). A social cognitive view of self-regulated learning and academic learning. Journal of Educational Psychology, 81(3), 329-339.

Zimmerman, B. J. (1990). Self-regulated learning and academic achievement: An overview. Educational Psychologist, 25, 3-17. 
Zimmerman, B. J. (1998). Academic studying and the development of personal skill: A self-regulatory perspective. Educational Psychologist, 33, 73-86.

Zimmerman, B. J. (1994). Dimensions of academic self-regulation: A conceptual framework for education. In D. H. Schunk \& B. J. Zimmerman (Eds.), Self-regulation of learning and performance: Issues and educational applications (pp. 3-21). Hillsdale, NJ: Erlbaum.

Zimmerman, B. J. (2000). Attaining self-regulation: A social cognitive perspective. In M. Boekaerts, P. R. Pintrich, \& M. Zeidner (Eds.), Handbook of self-regulation (Chap. 2) San Diego, CA: Academic Press.

Zimmerman, B. J., \& Martinez-Pons, M. (1986). Development of a structured interview for assessing student use of self-regulated learning strategies. American Educational Research Journal, 23, 614-628.

Zimmerman, B. J., and Moylan, A. R. (2009). "Self-regulation: where metacognition and motivation intersect," in Handbook of Metacognition in Education, eds D. J. Hacker, J. Dunlosky, and A. C. Graesser (New York, NY: Routledge), 299-315.

Zimmerman, B. J., \& Kitsantas, A. (1997). Developmental phases in self-regulation: Shifting from process to outcome goals. Journal of Educational Psychology, 89, 29-36. 